\title{
Performance of Enhanced Steel Beam-Column Welded Connections for Seismic Resistance
}

\author{
W. Aboalriha
}

\begin{abstract}
This paper presents and discusses the development of a numerical model which investigates the enhancement of overall stiffness and stress distribution in welded connections under cyclic loading. The structure under investigation, described in four fully welded T-joint (BCC5) specimens. The four specimens were modeled under different displacement loading using a finite element analysis program Solidworks and Ansys software in conjunction with test data obtained from the University of Lisbon, which was validated with the test results by matching the hysteresis loops, maximum high strain, and maximum stress at the crack location steel joint specimens. The comparison between the analysis and test results showed good agreement and also showed that the maximum strain in the enhanced model is less than the maximum strain on the base model, and the location of maximum strain is moved to the gusset plate rather than the weld zone, therefore the gusset plate makes the joint in the enhanced model more ductile than the joint in the base model. Life cycles to failure for the enhanced model are more than life cycles to failure in the base model. It is therefore found that this has useful applications in the steel construction industry.
\end{abstract}

Keywords - Finite element analysis, Steel structure, Beam to column welded connection, seismic loading, gusset plates, Ductility.

\section{INTRODUCTION}

After the 1994 Northridge and 1995 hijacking-nanbu (Kobe) earthquakes, engineers have highlighted the need for understanding and explaining some "unexpected" aspects of the seismic response exhibited by steel buildings during these events. In particular, the extensive damage and brittle failure modes occurred at beam-to-column welded connections of frame structures [1]. In the area of beam-column connection, a fairly high degree of uncertainty in the behavior of the joint exists. Therefore, it is necessary to understand the strength and rigidity of the connection region for the efficient design of steel building systems [2]. Steel connections can be classified by their strength as well as their ductility. The strength classification of connections is mostly based on the relative moment resistance of the connection compared to the moment resistance of the beam. Strength, rotation capacity, and ductility are essential for the connections, and deformation also governs the failure of a connection [2], [3].

A considerable number of experimental tests were conducted worldwide, to investigate the performance of steel connections under cyclic loading. A series of monotonic tensile tests on T-stub welded specimens were carried out.
The effects of weld fracture on the damage behavior of the connections were analyzed. The test results indicated that most brittle fractures initiate from welds; a weld's toughness has a significant influence on its ultimate deformation and cracking load [4].

The changes in the design lead to the constant improvement of the construction to get a less complex and low-cost structure, better material quality of the bearing and non-bearing part of the structure, using more effective techniques of analysis, changing the connection design through improving structural stability, safety and functionality.

The strengthening and ductility of the post-Northridge connection is achieved by either reinforcing the connection or weakening the beam section by one of the following; cover plates [5], triangular haunches [6], upstanding ribs [7], lengthened ribs [8], side plates [9] and adding slit dampers at the connection area as an additional energy dissipation source [10]. Weakening the beam section can be done either by cutting a portion of the beam flange (reduced beam section, RBS, connections) [11] or the beam web (wedge beam connections [12] and reduced beam web, RBW, connections [13]).

Among strengthening methods, one of the most common methods to enhance the ductility of rigid connections is using plates as shown in Fig. 1. This connection is named by Federal Emergency Management Agency (FE-MA350) aswelded flange plate (WFP) connection. In this connection, the applied moment and the shear forces are transferred to the column flange through the top and the bottom flange plates and a shear plate (also known as shear tab), respectively. The rectangular-shaped top and bottom flange plates have the same width and length [14].

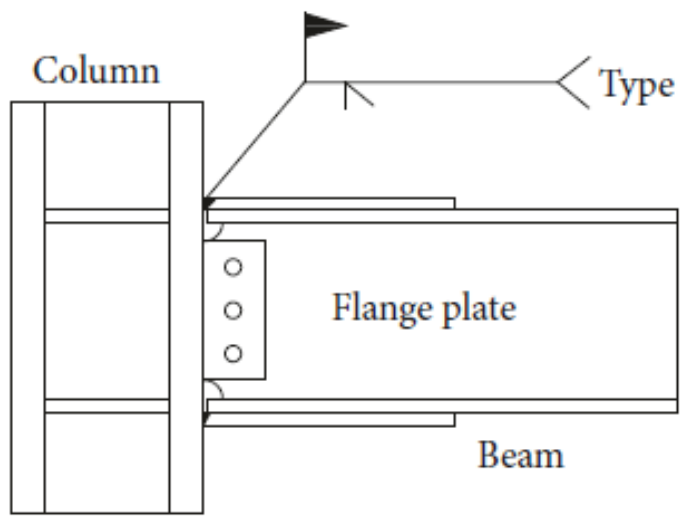

Fig. 1. Typical welded angle plate (WFP) connection [14]. 
Hedayat and Celikag [13], proposed the use of rectangular long voids at the beam web to enhance the connection ductility of post-Northridge connections as clearly seen in Fig. 2. This method was effective for beams with a maximum depth equal to $600 \mathrm{~mm}$. However, for deeper beams due to the high level of strain concentration at the reduced beam web $(\mathrm{RBW})$ area and excessive lateral-torsional buckling of the beam web (which was due to the increase in the depth of the voids), the efficiency of this method reduced, and the modified connection did not achieve adequate connection's strength and ductility [15].

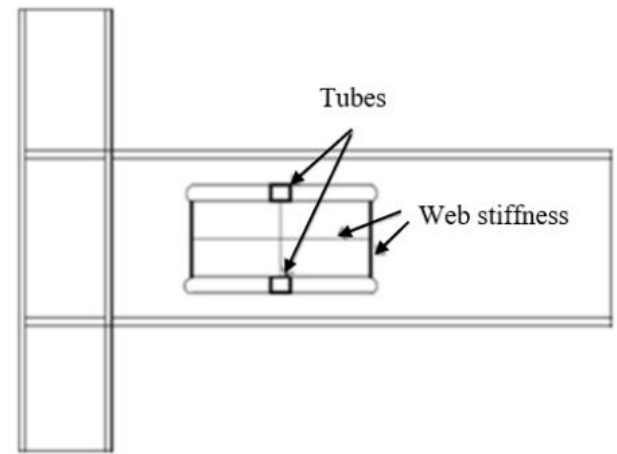

Fig. 2. Single longitudinal voids with stiffeners and tubes at the center of voids [15].

In this work, four numerical analyses of three-dimensional (3D) beam-column joints subjected to cyclic displacement loading were modeled using the FE technique and represented four fully welded rigid connection designs of a beam-column connection, and the results were validated with an experimental test. Gusset plates were added to the base model to increase both stiffness and connection ductility for improving the connection behavior. This will be referred to as an "enhanced model".

\section{A. Aims and Objectives}

This research work carried out by the author is aimed at studying the performance of enhanced steel beam-column welded connections for seismic resistance using four fully welded T-joint specimens (BCC5A, BCC5B, BCC5C and BCC5D).

\section{RESEARCH WORK RESULTS}

In this work, the fully welded beam-column connection (BCC5) tested under displacement control is described. The beam has a vertical I-section (a typical European beam section IPE300, which is considered equivalent to $\mathrm{W} 12 \times 30$ US, wide flange section), and the column is a horizontal Isection (HE160B equivalent to $\mathrm{W} 8 \times 24 \mathrm{US}$, wide flange section as illustrated in Table I. The cyclic displacement loading is applied to the beam in the horizontal direction, inplane; the column is fixed at both ends (rigid connection is one which fully transmits both moments and forces between the connected elements), which set the translation at zero as shown in Fig. 3 [Calado, 2010-2014, per. comm.].

The displacement was applied at a distance of $862.5 \mathrm{~mm}$ distance from the column top flange as illustrated in Fig. 4 as input to the Ansys non-linear analysis. Which were modeled by the author using Solid works and Ansys software as illustrated in Fig. 5 and 6 in conjunction with the test results [16], [Calado 2010-2014.per.comm]. Validation discusses in detail in the Author`s first published paper [17]. This was done by matching the hysteresis loops, maximum high strain, and maximum stress at the crack location of steel joint specimens [18]. The comparison between the analysis and test results showed good agreement.

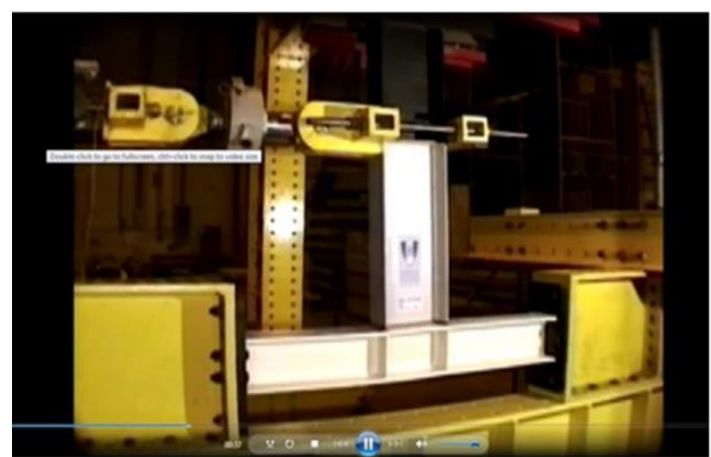

Fig. 3. Practical location of the beam to column connection laboratory Capture (Calado, 2010-2014, per.comm.).

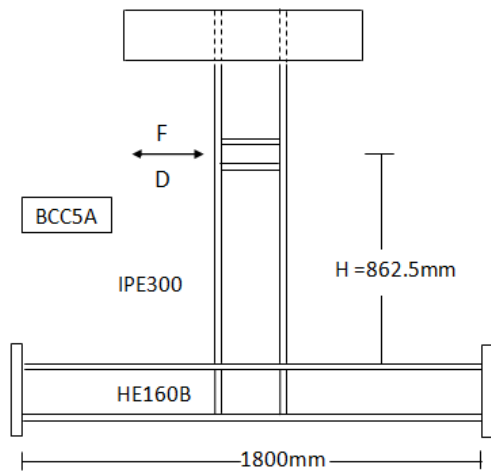

Fig. 4. Points of application of the displacement (D) and force measurement $(\mathrm{F})$

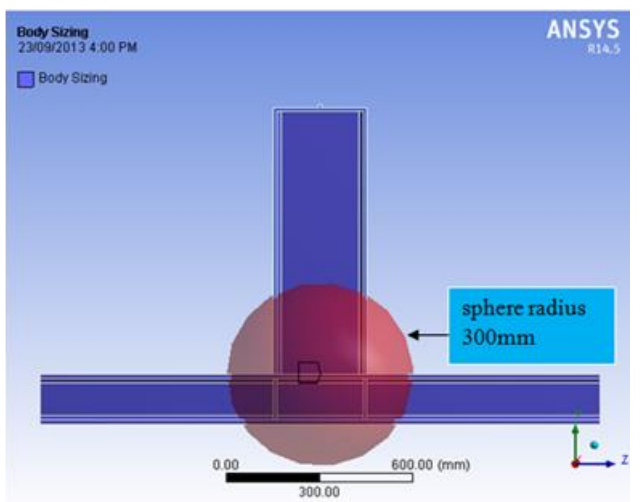

Fig. 5. Refine mesh in the welded joint sphere radius is $300 \mathrm{~mm}$ with $10 \mathrm{~mm}$ sizing.

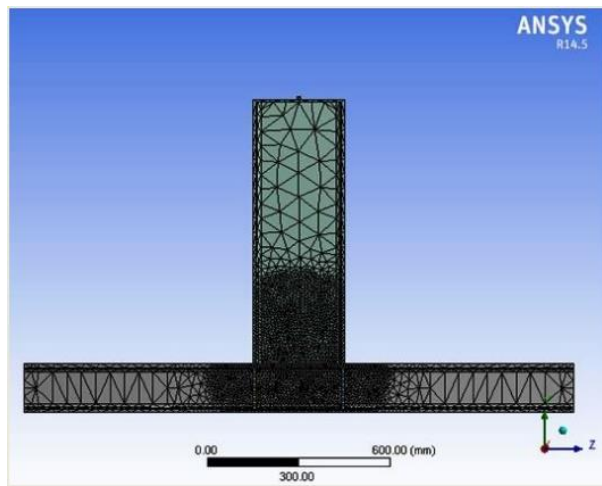

Fig. 6. Meshing and fine meshing using Ansys 14.5. 
TABLE I: BEAM AND COLUMN SECTIONS OF SPECIMENS AND COMPARISON TO U.S EQUiVALENT PROFILES [16]

\begin{tabular}{|c|c|c|c|c|c|c|c|c|c|}
\hline Element Section & $h(\mathrm{~mm})$ & $b_{f}(\mathrm{~mm})$ & $t_{w}(\mathrm{~mm})$ & $t_{f}(\mathrm{~mm})$ & $h_{\mathrm{w}} / t_{w}$ & $b_{f} / 2 t_{f}$ & Mass per Length $(\mathrm{kg} / \mathrm{m})$ & $I_{x x}\left(\mathrm{~cm}^{4}\right)$ & $Z_{x}\left(\mathrm{~cm}^{3}\right)$ \\
\hline Beam & & & & & & & & & \\
\hline IPE & 300 & 150 & 7.1 & 10.7 & 39.2 & 7.0 & 42.2 & 8356 & 628 \\
\hline $\begin{array}{c}\text { U.S section } \\
\text { W } 2 \text { X6.5X30 }\end{array}$ & 313 & 166 & 6.6 & 11.2 & 44.03 & 7.41 & 44.5 & 9934 & 708 \\
\hline $\begin{array}{c}\text { Column BCC5 } \\
\text { HE } 160 \text { B } \\
\text { U.S section }\end{array}$ & 160 & 160 & 8 & 13 & 16.75 & 6.15 & 42.6 & 2492 & 354 \\
\hline W $8 \times 6.5 \times 24$ & 210 & 165 & 6.2 & 10.2 & 29.13 & 8.09 & 36 & 3438 & 379 \\
\hline
\end{tabular}

\section{A. Comparison between the Base Model and Enhanced Model}

Gusset plates were added to the base model beam-column connection flanges. Their function is to enhance the connection between overall stiffness and stress distribution control. Fig. 7 shows the connection model with two bracing gussets on column web on each side (enhanced model). A fully welded connection includes two welded triangle plate gussets $125 \times 125 \times 10 \mathrm{~mm}$ thicknesses as flange bracing that is aligned with the webs of the beam and column. The plate gussets are defined as solid parts with the same material properties as the other elements of the connection.

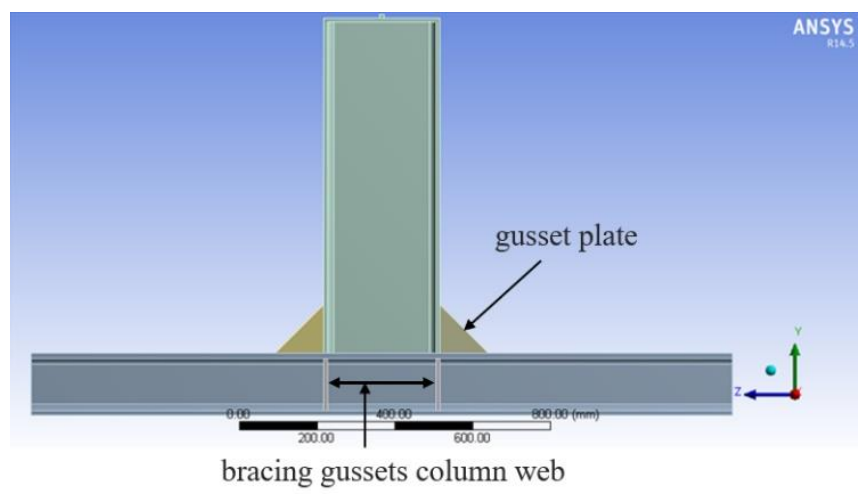

Fig. 7. Two triangles column - beam flange gusset plates and two bracing gussets column web in each side for enhanced model.

Table II illustrates that total strain amplitude and maximum normal stress results which are obtained from numerical analysis are reduced between (40-50\%) in the enhanced models which means that the life cycles of enhanced models are more than life cycles of base models as shown in Table IV.

Using strain life formulae to calculate a number of cycles to failure for the base and enhanced models for BCC5 models using Tables III and IV as follows:

Coffin-Manson formulas:

$$
\frac{\Delta \varepsilon}{2}=\frac{\sigma_{f}^{\prime}}{E}\left(2 N_{f}\right)^{b}+\varepsilon_{f}^{\prime}\left(2 N_{f}\right)^{c}
$$

Morrow and Smith et al.:

$$
\varepsilon_{a}=\frac{\sigma_{f}^{\prime}-\sigma_{\text {mean }}}{E}\left(2 N_{f}\right)^{b}+\varepsilon_{f}^{\prime}\left(2 N_{f}\right)^{c}
$$

Smith-Watson-Topper (SWT):

$$
\sigma_{\max } \varepsilon_{a} E=\left(\sigma_{f}^{\prime}\right)^{2}\left(2 N_{f}\right)^{2 b}+\sigma_{f}^{\prime} \varepsilon_{f}^{\prime} E\left(2 N_{f}\right)^{b+c}
$$

where

$\mathrm{E}$ is the modulus of elasticity;

$N_{f}$ is the number of cycles to failure.

It is noted that the strain life formulae are used for the plain structure. Modification for Fatigue Ductility Coefficient was made by dividing it by $5\left(\varepsilon_{f}^{\prime} / 5\right)$ to use these formulae for

\begin{tabular}{|c|c|c|c|c|}
\hline \multirow[t]{2}{*}{ Case no. } & \multicolumn{2}{|c|}{$\begin{array}{l}\text { Total Strain Amplitude using } \\
\text { Coffin-Manson Formula } \\
\varepsilon \mathrm{a}=\Delta \varepsilon / 2 \\
\end{array}$} & \multicolumn{2}{|c|}{$\begin{array}{c}\text { Maximum Normal } \\
\text { Stress (MPa) }\end{array}$} \\
\hline & Base & Enhanced & Base & Enhanced \\
\hline BCC5A & 0.0074 & 0.0043 & 606.45 & 470.19 \\
\hline ВСС $5 B$ & 0.100 & 0.0039 & 611.8 & 371.34 \\
\hline BCC5C & 0.0048 & 0.0022 & 553.6 & 430.1 \\
\hline BCC5D & 0.0053 & 0.0028 & 294.05 & 242.57 \\
\hline
\end{tabular}
welding structure considering strain hardening exponent (n') [17].

TABLE III: CyClic AND FAtigue Properties OF A Base, Weld, AND HEAT-AFFECTED MATERIALS FOR ASTM A36/E60s-3 WELDS [21]

\begin{tabular}{cc}
\hline Material & $\mathrm{A} 36-\mathrm{HAZ}$ \\
\hline Cyclic Strain Hardening Exponent, $\mathrm{n}^{\prime}$ & 0.215 \\
Fatigue Strength Coefficient, $\sigma_{f}^{\prime}$ & $724 \mathrm{MPa}$ \\
Fatigue Ductility Coefficient, $\varepsilon_{f}^{\prime}$ & 0.218 \\
Fatigue Strength Exponent, b & -0.066 \\
Fatigue Ductility Exponent, c & -0.492 \\
\hline
\end{tabular}

The difference between these formulae is that in Morrow and Smith et al. Formula the stress means $\left(\sigma_{\text {mean }}\right)$ is included, whereas in Smith-Watson-Topper (SWT) the maximum stress $\left(\sigma_{\max }\right)$ is included. In the current investigation, the total strain-time history was considered. The maximum stress was obtained from the normal to weld stress-time history. All the results were taken from FE analysis for the four cases at the critical point (known area of failure) in the model.

TABLE IV: NUMBER OF CYCLES TO FAILURE FOR BCC5 BASE AND ENHANCED MODELS USING STRAIN LIFE FORMULAS, INCLUDING ( $\left.\varepsilon_{f}^{\prime} / 5\right)$, CONSIDERING STRAIN HARDENING EXPONENT (n`)

\begin{tabular}{cccccccc}
\hline \multirow{2}{*}{ Case No. } & \multirow{2}{*}{$\begin{array}{c}\text { Experimental } \\
\text { work }\end{array}$} & \multicolumn{2}{c}{ Coffin Manson } & \multicolumn{2}{c}{$\begin{array}{c}\text { Morrow \& Smith } \\
\text { et. al. }\end{array}$} & \multicolumn{2}{c}{$\begin{array}{c}\text { Smith-Watson- } \\
\text { Topper (SWT) }\end{array}$} \\
\cline { 3 - 8 } & & Base & Enhanced & Base & Enhanced & Base & Enhanced \\
\hline BCC5A & 16 & 16 & 46 & 16 & 46 & 14 & 32 \\
BCC5B & 5 & 5 & 33 & 5 & 33 & 8 & 35 \\
BCC5C & 18 & 18 & 168 & 18 & 168 & 21 & 77 \\
BCC5D & 23 & 23 & 103 & 23 & 103 & 55 & 173 \\
\hline
\end{tabular}


There have been attempts to relate the Coffin-Manson exponent $\mathrm{c}$ with the cyclic strain hardening exponent $\mathrm{n}$ ` based on certain energy criteria. Morrow has shown that the exponents $\mathrm{c}$ and $\mathrm{b}$ can be related to $\left(\mathrm{n}^{\prime}\right)$ by:

$c=-1 /\left(1+5 n^{\prime}\right)$

$b=-n^{\prime} /\left(1+5 n^{\prime}\right)$

Tomkins has given the above relations as:

$c=-1 /\left(1+2 n^{\prime}\right)$

$b=-n^{\prime} /\left(1+2 n^{\prime}\right)$

therefore,

$\mathrm{b}=-0.150$ and $\mathrm{c}=-0.699$.

B. Displacement vs. Force Reaction Hysteresis Loops for FE ANSYS Base and Enhanced Models

Fig. 8-15 show displacement vs. force reaction hysteresis loops for FE ANSYS base models (red) and FE ANSYS enhanced models (black).

By comparing the data between the FE ANSYS base models force-displacement hysteresis loops which are subjected to the cyclic load with the FE ANSYS enhanced models force-displacement hysteresis loops, it can be shown that the enhanced model can resist loads bigger than the base model by around (30-40\%).

The additional forces in the last two columns in Table $\mathrm{V}$ are a result of the increased stiffness in the connection and the prescribed displacement time history remaining the same.

Table $\mathrm{V}$ shows that the maximum and minimum value of the applied force of the enhanced model in each model is more than the maximum and minimum values of the applied force for the FE ANSYS (base model) by (30-40\%) as shown in Table V.

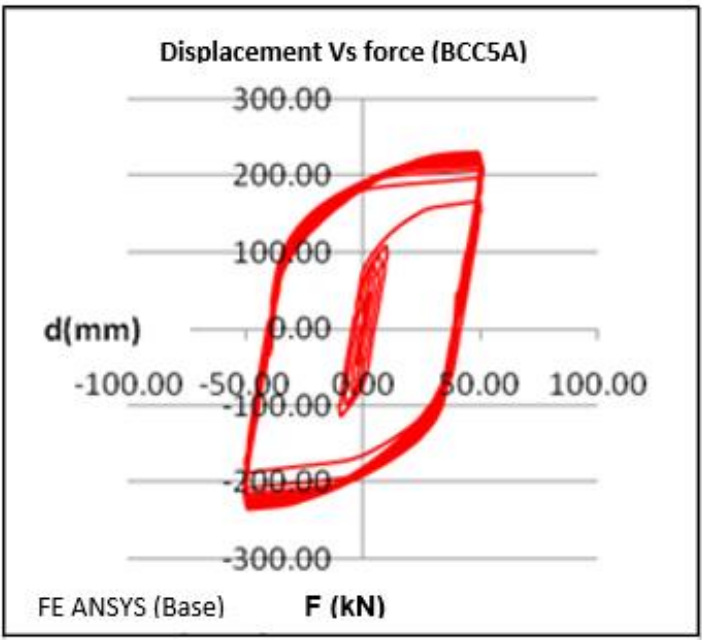

Fig. 8. Displacement Vs force reaction hysteresis loops for BCC5A, FE ANSYS base model.

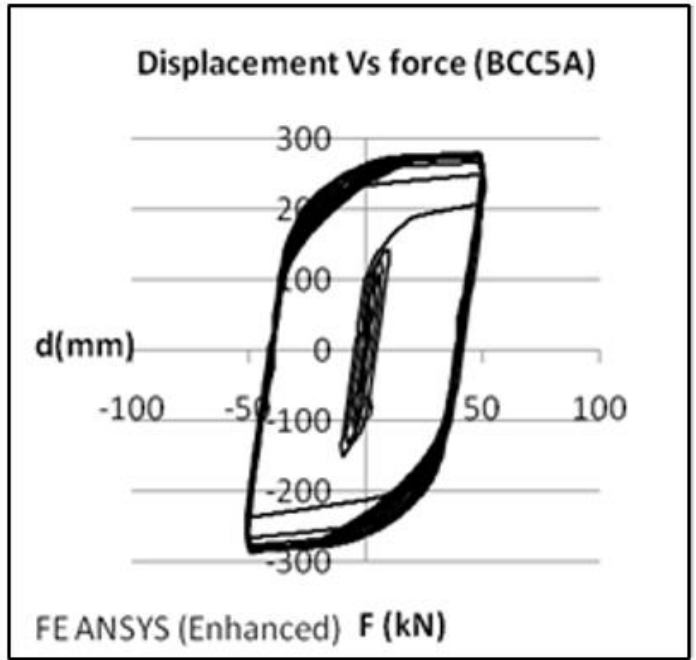

Fig. 9. Displacement Vs force reaction hysteresis loops for BCC5A, FE ANSYS enhanced model.

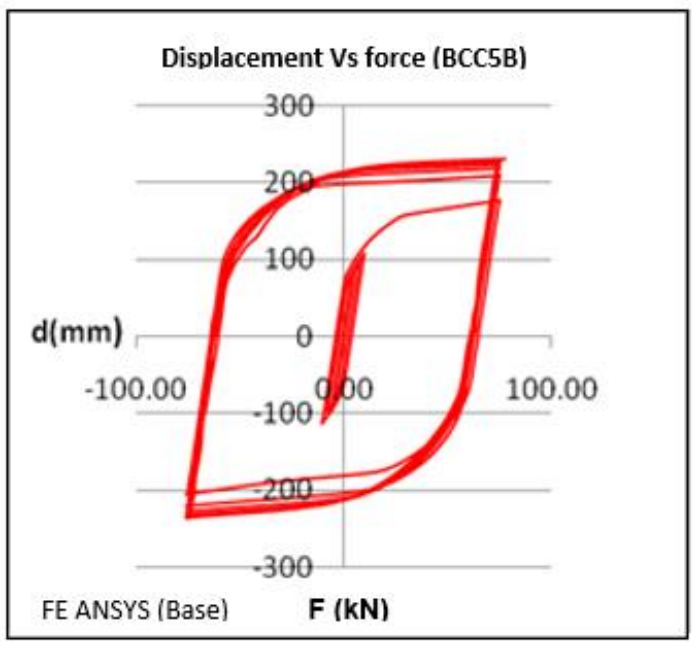

Fig. 10. Displacement Vs force reaction hysteresis loops for BCC5B, FE ANSYS base model.

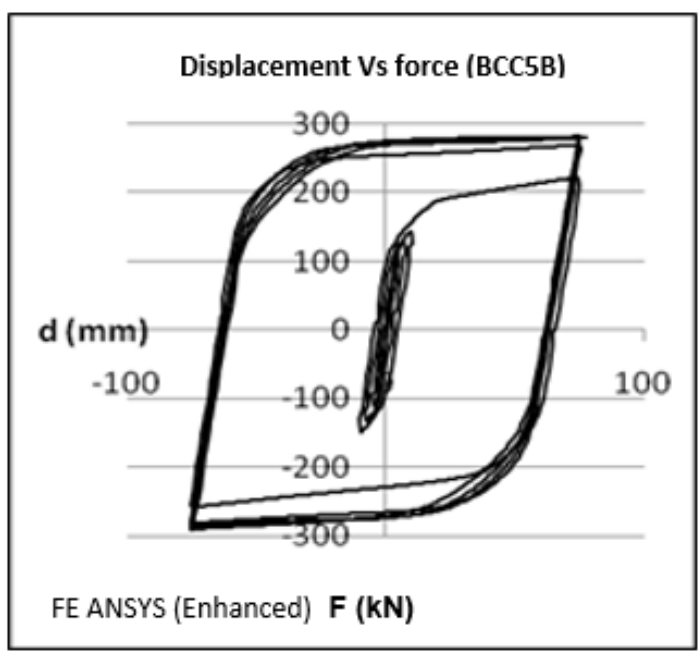

Fig. 11. Displacement Vs force reaction hysteresis loops for BCC5B, FE ANSYS enhanced model

TABLE V: MAXIMUM AND MINIMUM ForCES REPRESENT HYSTERESIS LOOPS FOR FE BASE AND ENHANCED MODELS

\begin{tabular}{ccccccc}
\hline Specimen no. & $\begin{array}{c}\text { FE Base max. } \\
\text { Force }(+\mathrm{KN})\end{array}$ & $\begin{array}{c}\text { FE Base Min. } \\
\text { Force }(-\mathrm{KN})\end{array}$ & $\begin{array}{c}\text { Enhanced Max. } \\
\text { Force }(+\mathrm{KN})\end{array}$ & $\begin{array}{c}\text { Enhanced Min. } \\
\text { Force }(-\mathrm{KN})\end{array}$ & $\begin{array}{c}\text { Difference Max. } \\
\text { Force }(+\mathrm{KN})\end{array}$ & $\begin{array}{c}\text { Difference Min. } \\
\text { Force }(-\mathrm{KN})\end{array}$ \\
\hline BCC5A & 190 & 181 & 254 & 245 & 64 & 64 \\
BCC5B & 208 & $\# 208$ & 272 & 272 & 64 & 64 \\
BCC5C & 195 & 198 & 255 & 258 & 60 & 60 \\
BCC5D & 168 & 163 & 235 & 230 & 67 & 67 \\
\hline
\end{tabular}




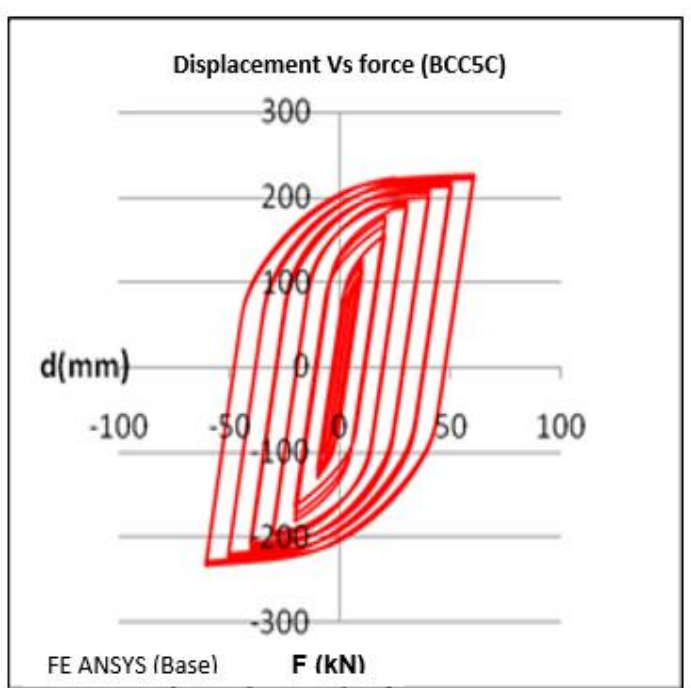

Fig. 12. Displacement Vs force reaction hysteresis loops for BCC5C, FE ANSYS base model

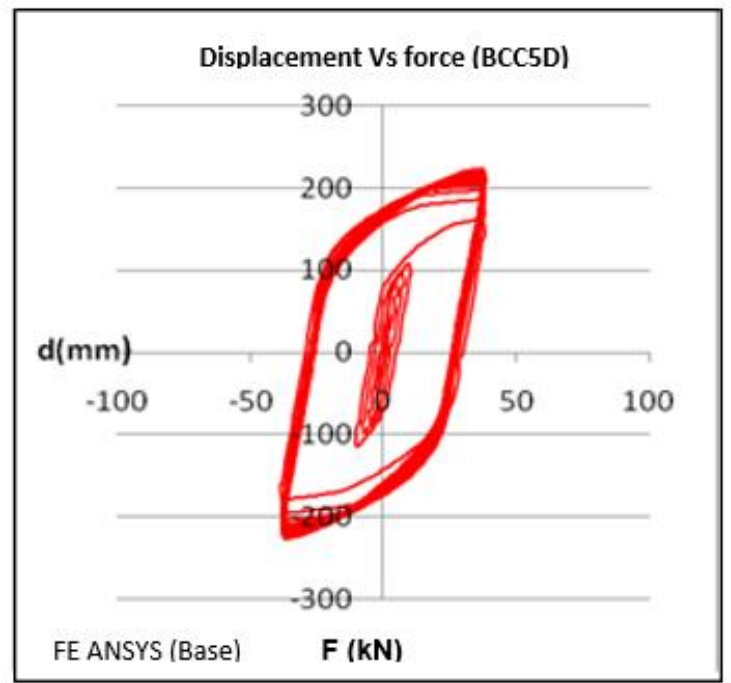

Fig.14. Displacement Vs force reaction hysteresis loops for BCC5D, FE ANSYS base model.

Table VI shows the total strain amplitude for the base models and the enhanced models and indicates that a failure occurred in the base model when the total strain amplitude reached the maximum value of $(0.00738)$ at cycle 16 of the BCC5A model. Also from Table VI, it can be seen that the total strain amplitude (is the elastic strain amplitude + the plastic strain amplitude) of the enhanced model has a lower value (0.0043) compared to the BCC5 base model and it's a strong indication that the enhanced model will perform better in an earthquake for longer (more than 16 cycles).

Table VI shows the same finding as the BCC5A model, in terms of the maximum total strain amplitude for the BCC5 FE ANSYS base and enhanced models.

TABLE VI: SHOWS THE DifFERENCE OF STRAIN AMPLITUdE FOR BASE AND ENHANCED MODELS OUTPUT FROM FE ANALYSIS FOR ALL BCC5

\begin{tabular}{cccc} 
Case & $\begin{array}{c}\text { Experimental } \\
\text { work }\end{array}$ & $\begin{array}{c}\text { Strain Amplitude } \\
\text { (Base model) }\end{array}$ & $\begin{array}{c}\text { Strain Amplitude } \\
\text { (Enhanced model) }\end{array}$ \\
No. & 16 & 0.00738 & 0.00431 \\
BCC5A & 5 & 0.01003 & 0.00399 \\
BCC5B & 18 & 0.00484 & 0.00224 \\
BCC5C & 23 & 0.00532 & 0.00282 \\
BCC5D & \multicolumn{3}{c}{} \\
\hline
\end{tabular}

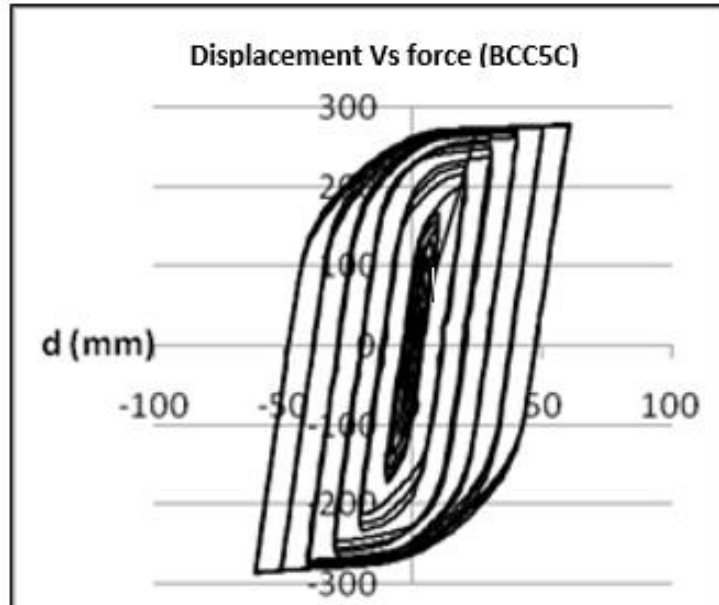

FE ANSYS (Enhanced) F (kN)

Fig.13. Displacement Vs force reaction hysteresis loops for BCC5C, FE ANSYS enhanced model.

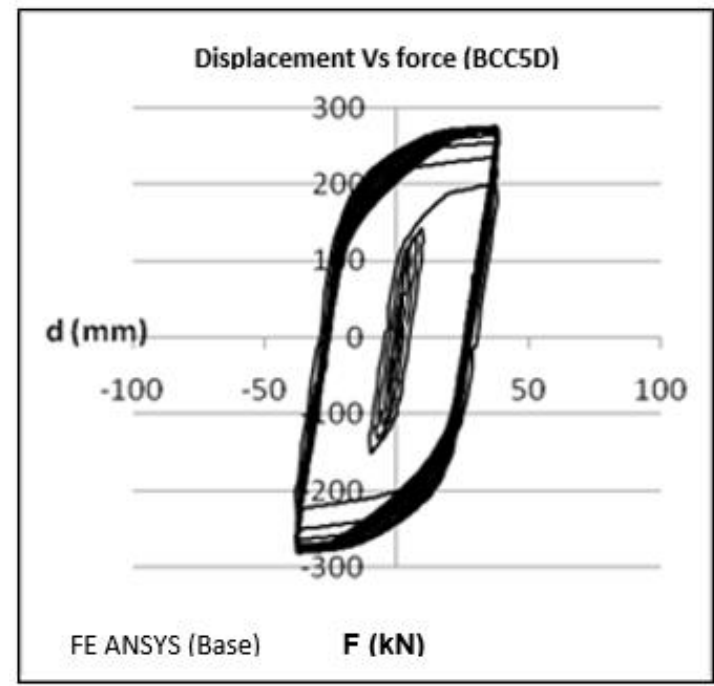

Fig.15. Displacement Vs force reaction hysteresis loops for BCC5D, FE ANSYS enhanced model.

\section{DISCUSSION}

The solution shows that using bracing gussets in column web results in an increase in stiffness, which results in additional forces under prescribed displacement conditions.

Nevertheless, there is an overall decrease in the total strain amplitude and normal stress as shown in Table II. As a result, the number of cycles to failure has increased for all enhanced models, in comparison with the base models, for all strain life formulas as shown in Table IV.

Table II indicates that a failure occurred in the base model of BCC5A when normal stress reached the maximum value of (606.45 MPa) at cycle 16 . Also, from the same table, it can be seen that the normal stress of the enhanced model has a lower value (470.19 $\mathrm{MPa}$ ) compared to the base model and it's a strong indication that the enhanced model has a longer working life (more than 16 cycles), same finding and indication applied to BCC5B, BCC5C, and BCC5D.

Table IV shows the number of cycles to failure, for the BCC5 FE base and enhanced models. The number of cycles to failure has increased in the enhanced model for all BCC5 models. By Applying the Coffin Manson formula, the results indicate that as a result of total strain and normal stresses 
decreasing in the enhanced model as shown in Table II; therefore, the connection performance has been improved.

Table IV shows a number of cycles to failure for the BCC5 base and enhanced models using strain life formulas, including $\left(\varepsilon_{f}^{\prime} / 5\right)$ considering strain hardening exponent (n '), Coffin-Manson and Morrow \& Smith et.al. [20]-[22] showed reasonable results for both BCC5 base and enhanced models.

Table VI shows a difference of strain amplitude for the base and enhanced models, which indicate that the enhanced model is not reaching the strain amplitude for the base model at the end of cycle life, which means that the cycle life for the enhanced model is longer than the cycle life of the base model for all enhanced models.

It was noted for all BCC5 models that the maximum high stress occurs in the panel zone, and that occurs due to shear stresses in the panel zone. The connection deformation for the enhanced model under the cyclic displacement loading gives the presented connection high rotational stiffness as a rigid type of connection [23].

A fillet/full penetration groove welds where the beam flange "connects" to the column flange, such a weld joint will induce stress concentrations at the weld toe, which will influence the fatigue endurance.

\section{CONCLUSION}

Based on the results presented in this paper, the following qualitative conclusions can be made:

1. The advantage of bracing gussets is that they reduce the stresses and strains as shown in Tables II and VI and move the highest strains away from the panel zone (bracing gussets as shown in Fig. 16-19 for BCC5), that is not affected by welding defects or heating, so it should also be better to be able to resist high cyclic strains.

2. The enhanced model showed that the maximum strain is less than that in the base model as shown in Table VI, and the location of maximum strain distribution is moved to the gusset plate rather than the weld zone as shown in Fig. 16, 17. Therefore, the gusset plates make the joint in the enhanced model more ductile than the joint in the base model. Life cycles to failure for the enhanced model are more than life cycles to failure base model.

3. The plastic hinges occur in the members framing into the joint and is moved away from the beam end.

4. The connection is more rigid, and this can be beneficial.

5. Rigid connections are needed when higher stiffness is required and in structures where additional bracing of the frame may be avoided by including

6. this type of connection presented in this paper. Regardless of the fact of the difficulties that may occur during manufacture, this is usually a designer's choice for connection in cases where greater rotational stiffness, shear capacity, and deformation capacity are needed [23].

7. The fully welded connections can give different characteristics that can change significantly if bracings or additional stiffeners are added. The numerical analysis makes it easier for the designers to explore the characteristics of the connection and make new connection designs.

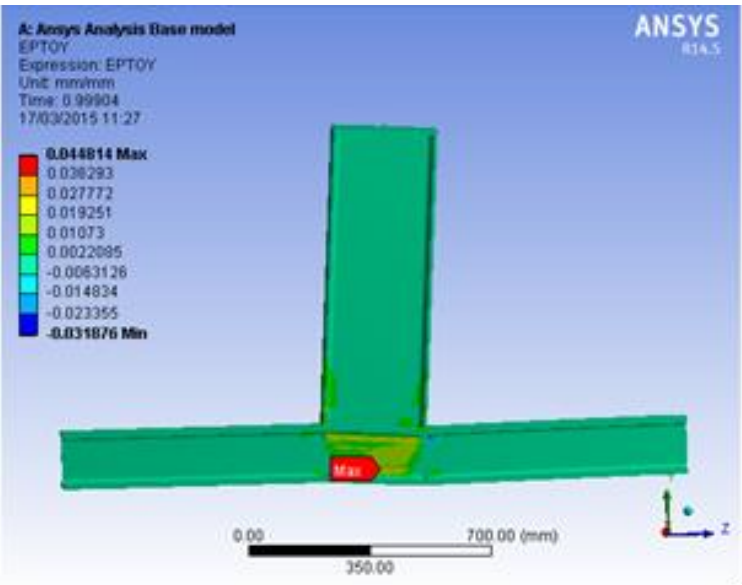

Fig. 16. Base model strain distribution.

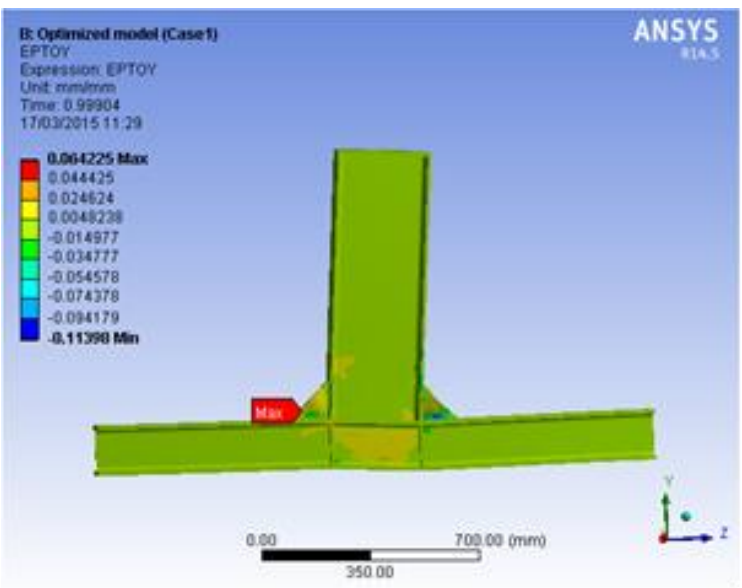

Fig. 17. Enhanced model strain distribution.

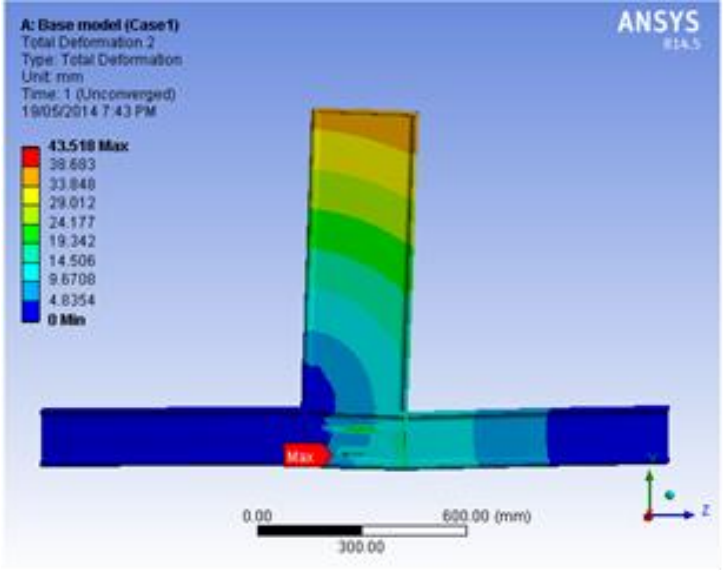

Fig. 18. Base model total deformation distribution

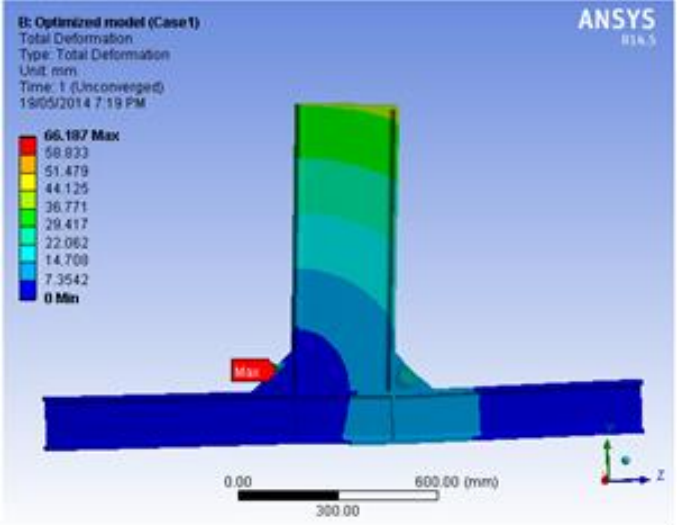

Fig. 19. Enhanced model total deformation distribution. 


\section{ACKNOWLEDGMENT}

The author would like to acknowledge the fact that this paper was carried out in collaboration with the author's Supervisor Prof Nigel Barltrop at the University of Strathclyde with the assistance of Prof Luis Calado at the University of Lisbon. The assistance of Dr. Philip Esper is appreciated.

\section{REFERENCES}

[1] H. Zhou, Y. Wang, L. Yang, and Y. Shi, Seismic low -cycle fatigue evaluation of welded beam to column connections in steel moment frames through global local analysis, International Journal of Fatigue, vol. 64, pp. 97-113, 2014. [Online]. Available: http://www.elsevier.com/locate/ijfatigue.

[2] L. Lois, and N. Babu, Numerical Analysis of Strength Behavior of Bolted Steel Beam Column Connection Based on Type and Position of Stiffeners, International Research Journal of Engineering and Technology (IRJET), vol. 04, Issue 04, 2017. ISSN 2395-0056 [Online]. Available: www.irjet.net.

[3] M. Fattouh, F. Shaker, M. Waseem, and A. Elrahman, Analytical Behavior of Steel Pre-tensioned Bolted Connections with Flushed and Extended End Plates under Bending, World Applied Sciences Journal, vol. 30 (6), pp. 673-684, 2014. doi: 10.5829/idosi. wasj. 2014.30.06.14091.

[4] L. Xi-yue, W. Yuan-qing, X. Jun, and S. Yong-Jiu, Damage behavior of steel beam-to-column connections under inelastic cyclic loading, Journal of Zhejiang University-SCIENCE A (Applied Physics \& Engineering), 2017. ISSN1862-1775 [Online]. Available: www.jzus.zju.edu.cn; www.springerlink.com.

[5] M.D. Engelhardt, and T.A. Sabol, Reinforcing of steel moment connections with cover plates: Benefits and limitations, Engineering Structures, vol. 20 (4-6), pp.510-520, 1998.

[6] B. Chia, C.M. Uang, and A. Chen, Seismic rehabilitation of preNorthridge steel moment connections: A case study, Journal of Constructional Steel Research, vol. 62, pp. 783-92, 2006.

[7] E.P. Popov, and K.C. Tsai, Performance of large seismic steel moment connections under cyclic loads, Engineering Journal, AISC, vol. 26 (2), pp. 51-60, 1989.

[8] C.C. Chen, J.M. Lee, and M.C. Lin, Behavior of steel moment connections with a single flange rib, Engineering Structures, vol. 25, pp. 1419-28, 2003.

[9] M.D. Engelhardt, and T.A. Sabol, Testing of welded steel moment connections in response to the Northridge earthquake. Northridge steel update 1, American Institute of Steel Construction, 1994.

[10] H. Saffari, A. Hedayat, and M.P. Nejad, Post-Northridge connections with slit dampers to enhance strength and ductility, Journal of Constructional Steel Research, vol. 80, pp. 138-152, 2013.

[11] E.P. Popov, T.S. Yang, and S.P. Chang, Design of steel MRF connections before and after 1994 Northridge earthquake, Engineering Structures, vol. 20, no. 12, pp. 1030-1038, 1998.

[12] S. Wilkinsona, G. Hurdmanb, and A. Crowtherb, A moment resisting connection for earthquake resistant structures, Journal of Constructional Steel Research, vol. 62, pp. 295-302, 2006.

[13] A.A. Hedayat, and M. Celikag, Post-Northridge connection with modified beam end configuration to enhance strength and ductility, Journal of Constructional Steel Research, vol. 65, no. 7, pp. 14131430, 2009.

[14] A.A. Hedayat, E. Jazebi, S. AsadAbadi, and A. Iranpour, Flexural Strength Prediction of Welded Flange Plate Connection Based on Slenderness Ratios of Beam Elements Using ANN. Advances in Civil Engineering, vol. 2018, Article ID 8059190, 17 pages, 2018. [online]. Available: https://doi.org/10.1155/2018/8059190.

[15] S. Naimi, M. Celikag, and A.A. Hedayat, Ductility Enhancement of Post-Northridge Connections by Multilongitudinal Voids in the Beam Web, The Scientific World Journal, vol. 2013, Article ID 515936, 14 pages, 2013. [Online]. Available http://dx.doi.org/10.1155/2013/515936.

[16] E. Mele, L. Calado and De Luca, An Experimental investigation on European welded connections. ASCE 129, Journal of Structural Engineering, 07339445, pp. 1301-1311, 2003.

[17] W. Aboalriha, N. Barltrop and L. Calado, Prediction of low cycle fatigue life of steel welded connection subjected to high cyclic strains, presented at the ICCIE, March 13-15, 2018, 2018. Ras Al Khaimah, UAE.
[18] Guide to fatigue design and assessment of steel structures, BS76082014.

[19] S. Raman, and V.M. Radhakrishnan, On cyclic stress-strain behaviour and low cycle fatigue life, Department of Metallurgical Engineering, Indian Institute of Technology, Madras, Chennai-600 036, Materials and Design 23 Ž. 249 254, India, 2002.

[20] L.F. Coffin, A Study of the effects of cyclic thermal stresses in a ductile metal, Trans. ASME, vol. 76, no. 6, August, pp. 931-949, discussion, pp. 949-950, 1954

[21] J. Morrow, Fatigue design handbook-Advances in Engineering. Warendale, PA, SAE, pp. 21-29, 1968

[22] J. Morrow, Cyclic plastic strain energy and fatigue of metals, internal friction, damping, and cyclic plasticity. ASTM STP 378, ASTM, West Conshohocken, pp. 45, 1965.

[23] B. Trajanoska, G. Arsova-Miloshevska, and Z. Bogatinoski, Numerical modelling of welded rigid beam-column connections at multi-story structures. Scientific proceedings VIII, international congress machines, Technologies, Materials, vol. 1, pp. 86-90, 2011 print ISSN:1310-3946.

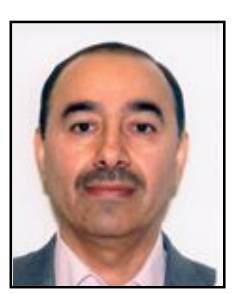

W. Aboalriha was born on 01- 07-1962 in Iraq. And he was awarded a Ph.D. in civil and environmental engineering from the University of Strathclyde, UK, Glasgow, 2015

His MSc in structural engineering and foundations obtained from the University of Westminster, UK, London, 1999.

His undergraduate degree BEng (Hons) in civil engineering obtained from the University of Westminster, UK, London, 1997.

In addition, Dr. Aboalriha is a member of the Society for Earthquake and Civil Engineering Dynamics (SECED), and also, he is a Member of the European Association for Earthquake Engineering (EAEE). 